\title{
A Continued Study on the Stealth Liposomal Topotecan Plus Amlodipine: In Vitro and In Vivo Characterization in Non-Resistant Solid Tumors
}

\author{
Yu-Teng Zhang, ${ }^{a}$ Wei Lu,${ }^{a, b}$ Ting Li, ${ }^{a}$ Gong-Wen Liang, ${ }^{a}$ Jia-Bei Sun, ${ }^{a}$ Jia Guo, ${ }^{a}$ \\ Ying Men, ${ }^{a} \mathrm{Ju} \mathrm{Du},{ }^{a}$ and Wan-Liang $\mathrm{Lu}^{a, b}, *$ \\ ${ }^{a}$ Department of Pharmaceutics, School of Pharmaceutical Sciences, Peking University, Xueyuan Road 38, Beijing 100083, China and \\ ${ }^{b}$ State Key Laboratory of Natural and Biomimetic Drugs, Peking University, Beijing 100083, China
}

(Received March 1, 2008; Accepted April 26, 2008)

\begin{abstract}
We have previously established a type of anti-resistant stealth liposomal topotecan plus amlodipine for overcoming the multi-drug resistance (MDR) in resistant leukemia cells. The objective of the present study was to further characterize it in the diversified non-resistant solid tumors in vitro and in vivo. Stealth liposomal topotecan plus amlodipine was re-prepared and physicochemically characterized. The in vitro drug release assays of topotecan and amlodipine from liposomes were performed using a dialysis method. 3-(4,5-dimethylthiazol-2-yl)-2,5-diphenyl tetrazolium bromide (MTT) assays were performed in murine sarcoma S180 cells and human breast cancer MCF-7 cells, respectively. Apoptotic percentages of S180 cells were evaluated using flow cytometry. In vivo anti-tumor activity study and terminal deoxynucleotidyl transferase-mediated dUTP-biotin nick end labeling (TUNEL) analysis were performed in male Institute of Cancer Research (ICR) mice with S180 xenografts. Stealth liposomal topotecan plus amlodipine exhibited high drug encapsulation efficiencies, suitable particle size distribution, negatively charged zeta potential and prolonged release profiles for both topotecan and amlodipine. Amlodipine potentiated the antiproliferative effect and inducing apoptotic effect of topotecan on the tumor cells, exhibiting an additive anti-tumor effect. Stealth liposomal topotecan plus amlodipine showed the optimal anti-tumor activity and inducing apoptotic effect in the in vivo studies. Stealth liposomal topotecan plus amlodipine demonstrated an overt anti-tumor activity in non-resistant solid tumors, suggesting that it deserves further clinical evaluations.
\end{abstract}

Key words — stealth liposomal topotecan plus amlodipine, solid tumors, anti-tumor activity, murine sarcoma cell line S180, human breast cancer cell line MCF-7

\section{INTRODUCTION}

A large number of anti-tumor agents including topotecan are becoming insensitive or even ineffective to tumor cells owing to multi-drug resistance (MDR), ${ }^{1-3)}$ which refers to a cross-resistance of tumor cells to not only a single type but also a series of structurally different anti-tumor drugs and is often found in a variety of human malignancies that have relapsed after initial treatment. ${ }^{2,4,5)}$ Since MDR has become one of the major causes leading to the failure of cancer chemotherapy, many studies are focused on the strategies to overcome MDR. ${ }^{6}$ )

As an attempt to circumvent MDR, we have pre-

*To whom correspondence should be addressed: Department of Pharmaceutics, School of Pharmaceutical Sciences Peking University, Xueyuan Road 38, Beijing 100083, China. Tel.: +86-10-8280-2683; $\quad$ Fax: +86-10-8280-2683; E-mail: luwl@bjmu.edu.cn viously established a type of anti-resistant stealth liposomal topotecan plus amlodipine through which we successfully incorporated topotecan with amlodipine together into stealth liposomes using the ammonium sulphate gradient method. ${ }^{1)}$ Topotecan was used as a cytotoxic agent and amlodipine was adopted as a "modulator," aiming at overcoming MDR caused by the overexpression of Pglycoprotein (P-gp or ABCB1) in human resistant leukemia cells (MDR HL-60 and MDR K562). Results demonstrated that amlodipine was an effective modulator capable of reversing the MDR in resistant leukemia cells in vitro and in vivo. In addition, amlodipine was able to enhance the antiproliferative and inducing apoptotic effects of topotecan in the related non-resistant leukemia cells (HL-60 and K562). We therefore anticipated the potential application of the stealth liposomal topotecan plus amlodipine in clinical use and postulated that amlodip- 
ine might also act as a potential anti-tumor agent which has the additive effect on topotecan in a diversified range of tumor cell lines.

Stealth liposomes or sterically-stabilized liposomes are able to diminish the hydrophobic interactions between plasma opsonins and liposome surface hence evading the in vivo uptake by the cells of the reticulo-endothelial system (RES) due to their surface modifications by flexible hydrophilic polymers with PEGylated lipid derivatives like polyethylene glycoldistearoylphosphatidylethanolamine, $\mathrm{PEG}_{2000^{-}}$ DSPE. ${ }^{7-11)}$ Therefore, stealth liposomes exhibit a series of beneficial biological properties in vivo. For instance, they have longer circulatory half lives in blood circulation and smaller distribution volumes in vivo compared with bare liposomes or free drug. ${ }^{7)}$ Stealth liposomes also have an improved ability to extravasate through the "pores" in the capillary endothelium of cancerous tissues leading to an enhanced vascular permeability and an increased accumulation in solid tumors. ${ }^{10,12)}$

Topotecan is a water-soluble anti-tumor agent derived from camptothecin, and effective for the treatment of colonic, ovarian, breast, small-cell and non-small cell lung cancers, acute leukemia as well as metastatic neuroblastoma. ${ }^{13,14)}$ As a cell cycle specific anti-tumor agent, topotecan has a putative anti-tumor mechanism in which it specifically inhibits the activity of nuclear enzyme topoisomerase I, a key enzyme essential to the process of DNA replication and transcription, triggering apoptosis of tumor cells by forming the single-strand and double-strand breaks. ${ }^{15)}$ In addition, topotecan is capable of inducing oxidative stress and in turn leading to apoptosis of tumor cells by generating oxygen free radicals. ${ }^{14)}$ Topotecan possesses $\alpha$-hydroxy- $\delta$-lactone ring undergoing a reversible hydrolysis at physiological conditions to an inactive open ring-carboxylate species. However, the carboxylate species can also be reversibly converted to the active lactone species in acidic conditions. ${ }^{13,15,16)}$ Therefore, it is predictable that the stealth liposomal encapsulation of topotecan into the inner weak acidic medium of liposomes would be beneficial for the protection of the active lactone species, leading to an enhanced anti-tumor efficacy.

Using "modulators" in combination with antitumor agents is a potential strategy to improve therapeutic index in cancer therapy. $3,14,17)$ Modulators or the MDR reversal agents refer to a wide pool of compounds that could inhibit the function of MDRrelated adenosine triphosphate (ATP)-binding cassette transporters (e.g., P-gp, multi-drug resistance associated protein (MRP), breast cancer resistance protein (BCRP), etc.) which actively evacuate the anti-tumor agents from tumor cells leading to decreased intracellular drug concentrations. ${ }^{18)}$ A number of agents have been demonstrated to be able to reverse MDR, such as verapamil, cyclosporineA, probenecid, elacridar (GG918) and valspodar (PSC-833). ${ }^{3,17,19)}$ However, studies showed that the toxicities of some modulators were too high due to their low reversing potencies and lack of sitespecificity. ${ }^{3)}$ Amlodipine is a relatively new dihydropyridine $\mathrm{Ca}^{2+}$ channel blocker that is clinically approved for the treatment of hypertension. ${ }^{20,21)}$ Compared with other $\mathrm{Ca}^{2+}$ channel blockers, the cardiotoxicity of amlodipine seems to be lower. ${ }^{22)}$ Therefore, amlodipine was selected as a MDR modulator in our previous study. Interestingly, amlodipine also exhibits substantial antiproliferative effect. For example, amlodipine is able to inhibit the growth and DNA synthesis of human epidermoid carcinoma A431 cells. ${ }^{20,21)}$

Two kinds of non-resistant solid tumor cell lines, including murine sarcoma cell line S180 and human breast cancer cell line MCF-7, have been extensively used for evaluating the anti-tumor activities of various anti-tumor agents. S180 is a highly malignant tumor cell line from mice and has been reported to be sensitive to 5 -fluorouracil $(5-\mathrm{FU}),{ }^{23)}$ doxorubicin ${ }^{24)}$ and wogonin, ${ }^{25)}$ but there is no report concerning whether topotecan or amlodipine is capable of inhibiting the growth of S180 cells. MCF-7 is a well-established human breast cancer cell line which was originally developed in $1973,{ }^{26)}$ and previously reported to be vulnerable to cyclophosphamide (CPA), ${ }^{27)}$ artelastinn $^{28)}$ and triethylene tetramine (TETA). ${ }^{29)}$ Topotecan has also been demonstrated to be effective in inhibiting the growth of MCF-7 cells but it is still unknown whether its anti-tumor effect could be potentiated by amlodipine.

Therefore, the objectives of the present study were to further characterize the stealth liposomal topotecan plus amlodipine in the non-resistant solid tumors in vitro and in vivo.

\section{MATERIALS AND METHODS}

Chemicals — Topotecan hydrochloride was pur- 
chased from Chengdu Furunde Enterprise Co., Ltd. (Sichuan, China). Amlodipine besylate was kindly provided by Beijing Yimin Pharmaceuticals, Co., Ltd. (Beijing, China). Egg phosphatidylcholine (EPC) and $\mathrm{PEG}_{2000}$-DSPE were purchased from NOF Corporation (Tokyo, Japan). Cholesterol was purchased from Beijing Shuangxuan Microbial Media Products Plant (Beijing, China). 3(4,5-dimethylthiazol-2-yl)-2,5-diphenyl tetrazolium bromide (MTT) was purchased from Biodee Biotechnology Co., Ltd. (Beijing, China).

Analytical Methods for Topotecan and Amlodipine - Topotecan concentrations were measured using fluorospectrophotometry method. The excitation wavelength was set at $381 \mathrm{~nm}$ and the emission wavelength at $531 \mathrm{~nm}$. The limit of quantification (LOQ) was $3.2 \mathrm{ng} / \mathrm{ml}$ and linearity ranged from $0.05-1.0 \mu \mathrm{g} / \mathrm{ml}\left(R^{2}=0.9997\right)$.

Amlodipine concentrations were measured using high performance liquid chromatography (HPLC) method, as reported previously. ${ }^{22)} \mathrm{An} \mathrm{Ag-}$ ilent 1100 series HPLC system with a UV detector was performed at $25^{\circ} \mathrm{C}$ using an Agela Technologies Inc (AGT), (Newark, Delaware USA), BonChrom C18 column $(250 \mathrm{~mm} \times 4.6 \mathrm{~mm}, 5 \mu \mathrm{m})$ with a run time of $10 \mathrm{~min}$ at the flow rate of $1 \mathrm{ml} / \mathrm{min}$. The mobile phase system was consisted of water (containing $0.03 \mathrm{M} \mathrm{KH}_{2} \mathrm{PO}_{4}$ ) and methanol $(25: 75, \mathrm{v} / \mathrm{v})$ and the detection wavelength was set at $237 \mathrm{~nm}$. The LOQ was $0.03 \mu \mathrm{g} / \mathrm{ml}$ and linearity ranged from $0.5-30.0 \mu \mathrm{g} / \mathrm{ml}\left(R^{2}=0.9999\right)$.

Preparation of Liposomes - Six kinds of liposomes were prepared using the ammonium sulfate gradient method according to our previous report, ${ }^{1,16)}$ including (a) bare liposomal topotecan, (b) bare liposomal amlodipine, (c) bare liposomal topotecan plus amlodipine, (d) stealth liposomal topotecan, (e) stealth liposomal amlodipine, (f) stealth liposomal topotecan plus amlodipine. The stealth liposomes were composed of EPC, cholesterol and PEG $_{2000}$-DSPE $(55: 40: 5, \mu \mathrm{mol})$, while bare liposomes comprised EPC and cholesterol $(60: 40, \mu \mathrm{mol})$. The lipid concentration of both kinds of liposomes was approximately $10 \mu \mathrm{mol} / \mathrm{ml}$. The liposomes from (a) to (f) were used for comparisons.

Topotecan and/or amlodipine concentrations in the liposomes were less than $1.5 \mathrm{mg} / \mathrm{ml}$ to ensure high drug encapsulation efficiencies. Typically, the encapsulation efficiencies for topotecan and amlodipine were $\geq 95 \%$ and $90 \%$, respectively.
Size and Zeta Potential Distribution — The mean particle size, polydispersity index (PDI) and zeta potential of two types of liposomes were measured using Zetasizer 3000HSA (Malvern Instruments Ltd., Malvern, Worcestershire, U.K.). ${ }^{30,31)}$ Briefly, bare liposomal topotecan $(0.5 \mathrm{mg} / \mathrm{ml})$ plus amlodipine $(0.5 \mathrm{mg} / \mathrm{ml})$ and stealth liposomal topotecan $(0.5 \mathrm{mg} / \mathrm{ml})$ plus amlodipine $(0.5 \mathrm{mg} / \mathrm{ml})$ were diluted approximately 30 times using deionized water before adding into the sample cells. The measurements were performed at $25^{\circ} \mathrm{C}$ and each was repeated in triplicate.

Drug Release — In vitro drug release assays of topotecan and amlodipine from both bare liposomes and stealth liposomes were performed using a dialysis method. ${ }^{11,30,31)}$ Briefly, bare liposomal topotecan $(0.5 \mathrm{mg} / \mathrm{ml})$ plus amlodipine $(0.5 \mathrm{mg} / \mathrm{ml})$ and stealth liposomal topotecan $(0.5 \mathrm{mg} / \mathrm{ml})$ plus amlodipine $(0.5 \mathrm{mg} / \mathrm{ml})$ were pre-dialyzed in Hepes buffered saline (HBS, $25 \mathrm{mM}$ Hepes/150 $\mathrm{mM} \mathrm{NaCl}$ ) using dialysis tubings (molecular weight cutoff 14000) to remove any free topotecan and amlodipine. A volume of $2 \mathrm{ml}$ bare liposomal topotecan plus amlodipine or stealth liposomal topotecan plus amlodipine was mixed with $2 \mathrm{ml}$ blank murine plasma and the mixture was then placed into the same kind of dialysis tubing. Both bare and stealth liposomes-loaded dialysis tubings were placed into two beakers containing $50 \mathrm{ml} \mathrm{HBS}$, respectively. The beakers were incubated with water bath at $37^{\circ} \mathrm{C}$. At various time points including $0 \mathrm{~min}, 5 \mathrm{~min}, 15 \mathrm{~min}, 30 \mathrm{~min}, 1 \mathrm{hr}, 2 \mathrm{hr}, 4 \mathrm{hr}$, $6 \mathrm{hr}, 8 \mathrm{hr}, 10 \mathrm{hr}, 12 \mathrm{hr}, 24 \mathrm{hr}$ and $48 \mathrm{hr}$, aliquots of samples were carefully withdrawn from the beakers and then replaced with equal volume of HBS, respectively. Afterwards, concentrations of released topotecan and amlodipine were measured using fluorospectrophotometry method and HPLC method, respectively. The release rate $(\%)$ was calculated using the following formula: the release rate for topotecan or amlodipine $=\left(W_{n} / W\right) \times 100 \%$, where $W_{n}(\mu \mathrm{g})$ was the released amount of topotecan or amlodipine in the release medium and $W(\mu \mathrm{g})$ was the gross amount of topotecan or amlodipine added in the liposomes.

Cell Culture — Murine sarcoma cell line S180 was grown in the presence of $5 \% \quad \mathrm{CO}_{2}$ at $37^{\circ} \mathrm{C}$ and RPMI-1640 culture medium supplemented by $10 \%$ heat-inactivated fetal bovine serum (FBS) containing antibiotics (penicillin $100 \mathrm{U} / \mathrm{ml}$, streptomycin $100 \mu \mathrm{g} / \mathrm{ml}$ ) and L-Glutamine (Beijing Tianrun Shan-da Biotechnology Co., Ltd., Beijing, 
China). The culture conditions for human breast cancer cell line MCF-7 were similar to that of S180, but the culture medium was Dulbecco's modified Eagle's medium (DMEM) instead. Both cell lines were maintained in culture flasks and serial passages were conducted twice or three times weekly. MTT Assays — To determine whether amlodipine has the antiproliferative effect on S180 and MCF-7 cells and whether amlodipine potentiates the antiproliferative effect of topotecan, MTT assays were performed to evaluate the antiproliferative effects of various amlodipine formulations and various topotecan formulations co-treated with the same amlodipine formulations according to previous studies ${ }^{32,33)}$ with slight modifications.

S180 cells were seeded into 96-well plates at the concentration of $2 \times 10^{4}$ cells per well. Afterwards, a series of drug formulations were added into the wells, including fresh culture medium containing topotecan $(0-20 \mu \mathrm{M})$, amlodipine $(0-50 \mu \mathrm{M})$, mixtures of various concentrations of free topotecan $(0-20 \mu \mathrm{M})$ co-treated with free amlodipine $(0-30 \mu \mathrm{M})$, bare liposomal topotecan $(0-20 \mu \mathrm{M})$, bare liposomal amlodipine $(0-50 \mu \mathrm{M})$, mixtures of various concentrations of bare liposomal topotecan $(0-20 \mu \mathrm{M})$ co-treated with bare liposomal amlodipine $(30 \mu \mathrm{M})$, stealth liposomal topotecan $(0$ $20 \mu \mathrm{M})$, stealth liposomal amlodipine $(0-50 \mu \mathrm{M})$, mixtures of various concentrations of stealth liposomal topotecan $(0-20 \mu \mathrm{M})$ co-treated with stealth liposomal amlodipine $(30 \mu \mathrm{M})$. Cells incubated with medium without any drug were used as controls. After the addition of drugs, cells were further incubated for $43 \mathrm{hr}$ and $20 \mu \mathrm{l} /$ well MTT $(5 \mathrm{mg} / \mathrm{ml})$ was added. The plates were incubated for an additional $5 \mathrm{hr}$. The cells were then lysed using $100 \mu \mathrm{l}$ of sodium dodecylsulphate (SDS) solution (SDS $10 \mathrm{~g}$, isobutyl alcohol $5 \mathrm{ml}, 10 \mathrm{~mol} / \mathrm{l} \mathrm{HCl} 0.1 \mathrm{ml}$, deionized water added to $100 \mathrm{ml}$ ) and placed overnight in the incubator as above.

The operation procedures for MCF-7 cells were similar to those of $\mathrm{S} 180$ cells, but the concentration of cells seeded per well was $1 \times 10^{4}$ and drugs were added $24 \mathrm{hr}$ after cells were planted into the wells. In addition, after MTT was added into the wells for $5 \mathrm{hr}$, the above medium was removed completely and then $200 \mu$ l of dimethyl sulphoxide (DMSO) was added into each well instead of $100 \mu \mathrm{l}$ SDS solution.

The absorbance values of the wells were read on a microplate reader (Model 680, BIO-RAD laboratories, Tokyo, Japan) at the wavelength of $540 \mathrm{~nm}$.
The percentage of viable cells was calculated by the following formula: the percentage of viable cells $(\%)=\left(\mathrm{A}_{540 \mathrm{~nm}}\right.$ treated cells $/ \mathrm{A}_{540 \mathrm{~nm}}$ control cells) $\times 100 \%$, where $\mathrm{A}_{540 \mathrm{~nm}}$ was the absorbance value at $540 \mathrm{~nm}$.

\section{Apoptosis Assessment by Flow Cytometry}

To evaluate the inducing apoptotic effects of various topotecan and/or amlodipine formulations, flow cytometry assays were adopted to detect the apoptotic percentages of S180 cells. The Annexin V/propidium iodide (PI) staining procedures were operated according to the instructions of Annexin V-fluorescein isothiocyanate (FITC) staining kit (Biosea Biotechnology Co., Ltd., Beijing, China).

In brief, S180 cells were seeded into 6-well plates at the concentration of $5 \times 10^{5}$ cells per well. Twelve hours later, various formulations of drugs were added, including fresh culture medium as a control, free topotecan $(0-20 \mu \mathrm{M})$, free amlodipine $(0-50 \mu \mathrm{M})$, mixtures of free topotecan $(2.5 \mu \mathrm{M})$ cotreated with free amlodipine $(0-50 \mu \mathrm{M})$, bare liposomal topotecan $(2.5 \mu \mathrm{M})$, mixtures of bare liposomal topotecan $(2.5 \mu \mathrm{M})$ co-treated with bare liposomal amlodipine $(0-50 \mu \mathrm{M})$, stealth liposomal topotecan $(2.5 \mu \mathrm{M})$, mixtures of stealth liposomal topotecan $(2.5 \mu \mathrm{M})$ co-treated with stealth liposomal amlodipine $(0-50 \mu \mathrm{M})$. After additing drugs, the cells were further incubated for $12 \mathrm{hr}$, transferred to the tubes and centrifuged at 1000 revolutions per minute for $10 \mathrm{~min}$. The above medium was then removed and the cells washed three times using cold phosphate buffered saline (PBS, $0.13 \mathrm{M} \mathrm{NaCl}, 7 \mathrm{mM} \mathrm{Na} \mathrm{HPO}_{4}, 3 \mathrm{mM} \mathrm{NaH} \mathrm{PO}_{4}$, $\mathrm{pH}=7.4$ ). A volume of $200 \mu \mathrm{l}$ binding buffer was added to re-suspend the collected cells. An aliquot of $10 \mu \mathrm{l}$ Annexin V-FITC and $5 \mu \mathrm{l}$ PI were added. After incubation in the dark at room temperature for $15 \mathrm{~min}$, the apoptotic cells were measured by flow cytometry. ${ }^{1)}$

Anti-tumor Activity In Vivo and terminal deoxynucleotidyl transferase-mediated dUTPbiotin nick end labeling (TUNEL) Analysis Male Institute of Cancer Research (ICR) mice, initially weighing about $18 \mathrm{~g}$, were purchased from the Animal Laboratory Center of Peking University Health Science Center (Beijing, China). All care and handling of animals were performed with the approval of Institutional Authority for Laboratory Animal Care of Peking University.

S180 cells were maintained by serial passages of ascitic fluid weekly. Briefly, the ascitic fluid containing S180 cells was extracted from peritoneal 
cavity of the tumor-bearing mice and diluted two or three times using sterile physiological saline, and $0.2 \mathrm{ml}$ of the diluted suspension was injected intraperitoneally per mouse. ${ }^{24)}$

To evaluate the comparative anti-tumor activities of various drug formulations, male ICR mice were used to establish the in vivo xenograft models. Approximately $2 \times 10^{6} \mathrm{~S} 180$ cells derived from ascitic fluid were subcutaneously injected into the right armpits of mice. The mice were monitored daily for their tumor volumes $(V$, calculated by the following formula: $V=$ length $\times$ width $\left.\times 0.52, \mathrm{~mm}^{3}\right)$ and divided into seven groups (5 or 6 each group) on the 6th day. ${ }^{1)}$ In addition, on the 6th, 8th and 10th day after tumor inoculation, physiological saline, free topotecan $(5 \mathrm{mg} / \mathrm{kg})$, free amlodipine $(3 \mathrm{mg} / \mathrm{kg})$, free topotecan $(5 \mathrm{mg} / \mathrm{kg})$ plus free amlodipine $(3 \mathrm{mg} / \mathrm{kg})$, bare liposomal topotecan $(5 \mathrm{mg} / \mathrm{kg})$, stealth liposomal topotecan $(5 \mathrm{mg} / \mathrm{kg})$ and stealth liposomal topotecan $(5 \mathrm{mg} / \mathrm{kg})$ plus amlodipine $(3 \mathrm{mg} / \mathrm{kg})$ were given to mice via tail vein, respectively. The change ratio for tumor volume, as an indicator of anti-tumor activities, was calculated using the following formula: the change ratio for tumor volume $(\%)$ on the $n$th day $=$ $100 \times\left(V_{n \text {th }}-V_{\text {tth }}\right) / V_{6 \text { th }}$, where $V_{n \text {th }}$ represented the tumor volume on the $n$th day and $V_{6 \text { th }}$ indicated the tumor volume on the 6th day.

Tumor-bearing mice were sacrificed on the 13th day by cervical dislocation. After the tumorbearing mice were sacrificed, tumors from the physiological saline, free topotecan, stealth liposomal topotecan and stealth liposomal topotecan plus amlodipine treated groups were carefully isolated and fixed for analysis using TUNEL assay (terminal deoxynucleotidyl transferase-mediated dUTPbiotin nick end labeling). DNA fragmentation in the isolated tumors was visualized using an ApopTag plus peroxidase in situ apoptosis detection kit (Intergen Co Ltd., Burlington, MA, U.S.A.). The procedure was performed according to the instructions of the manufacturer. Under the light microscope, apoptotic cells showed brownish staining in the nuclei. The digital images of non-necrotic zone were randomly selected in the tissue sections.

Statistics — Values are presented as mean \pm standard deviation (S.D.) or mean \pm standard error (S.E.). One-way analysis of variance (ANOVA) was adopted to determine the significance among groups, after which post hoc tests with the Bonferroni correction were used for comparison between individual groups. A value of $p<0.05$ was consid- ered to be significant.

\section{RESULTS}

\section{Size and Zeta Potential Distribution}

The mean particle size, PDI and zeta-potential values are presented in Table 1. Results showed that the mean particle size of stealth liposomal topotecan plus amlodipine $(117.8 \pm 0.6 \mathrm{~nm})$ was significantly smaller than that of bare liposomal topotecan plus amlodipine $(160.5 \pm 0.5 \mathrm{~nm})$. In addition, the PDI value of stealth liposomal topotecan plus amlodipine $(0.173 \pm 0.006)$ was significantly lower than that of bare liposomal topotecan plus amlodipine $(0.248 \pm 0.003)$, indicating that the former had more homogenous particle size distribution. Furthermore, the absolute zeta potential value of stealth liposomal topotecan plus amlodipine $(-18.96 \pm 0.52 \mathrm{mV})$ was 3.91 times higher than that of bare liposomal topotecan plus amlodipine $(-4.844 \pm 0.276 \mathrm{mV})$.

\section{Drug Release}

The results from in vitro drug release assays are depicted in Fig. 1. In murine plasma, evident differences between the release profiles of bare liposomal topotecan plus amlodipine and stealth liposomal topotecan plus amlodipine were observed within $48 \mathrm{hr}$ incubation period. Compared with stealth liposomal topotecan plus amlodipine, bare liposomal topotecan plus amlodipine exhibited a faster release rate for both agents. For example, after $24 \mathrm{hr}$ incubation with murine plasma at $37^{\circ} \mathrm{C}$, $16.73 \%$ topotecan and $8.67 \%$ amlodipine released from bare liposomal topotecan plus amlodipine, respectively. However, at the same time point, only $3.26 \%$ topotecan and $2.25 \%$ amlodipine did from stealth liposomal topotecan plus amlodipine, respectively. In addition, the encapsulated amlodip-

Table 1. The Particle Size, PDI and Zeta Potential Values of Bare Liposomal Topotecan Plus Amlodipine and Stealth Liposomal Topotecan Plus Amlodipine

\begin{tabular}{lcc}
\hline \hline & $\begin{array}{c}\text { Bare liposomal } \\
\text { topotecan plus } \\
\text { amlodipine }\end{array}$ & $\begin{array}{c}\text { Stealth liposomal } \\
\text { topotecan plus } \\
\text { amlodipine }\end{array}$ \\
\hline Particle size $(\mathrm{nm})$ & $160.5 \pm 0.5$ & $117.8 \quad \pm 0.6$ \\
Polydispersity index & $0.248 \pm 0.003$ & $0.173 \pm 0.006$ \\
Zeta potential $(\mathrm{mV})$ & $-4.844 \pm 0.276$ & $-18.96 \quad \pm 0.52$ \\
\hline Each type of liposomes was measured for three times. Data are \\
presented as mean \pm S.D. $(n=3)$.
\end{tabular}



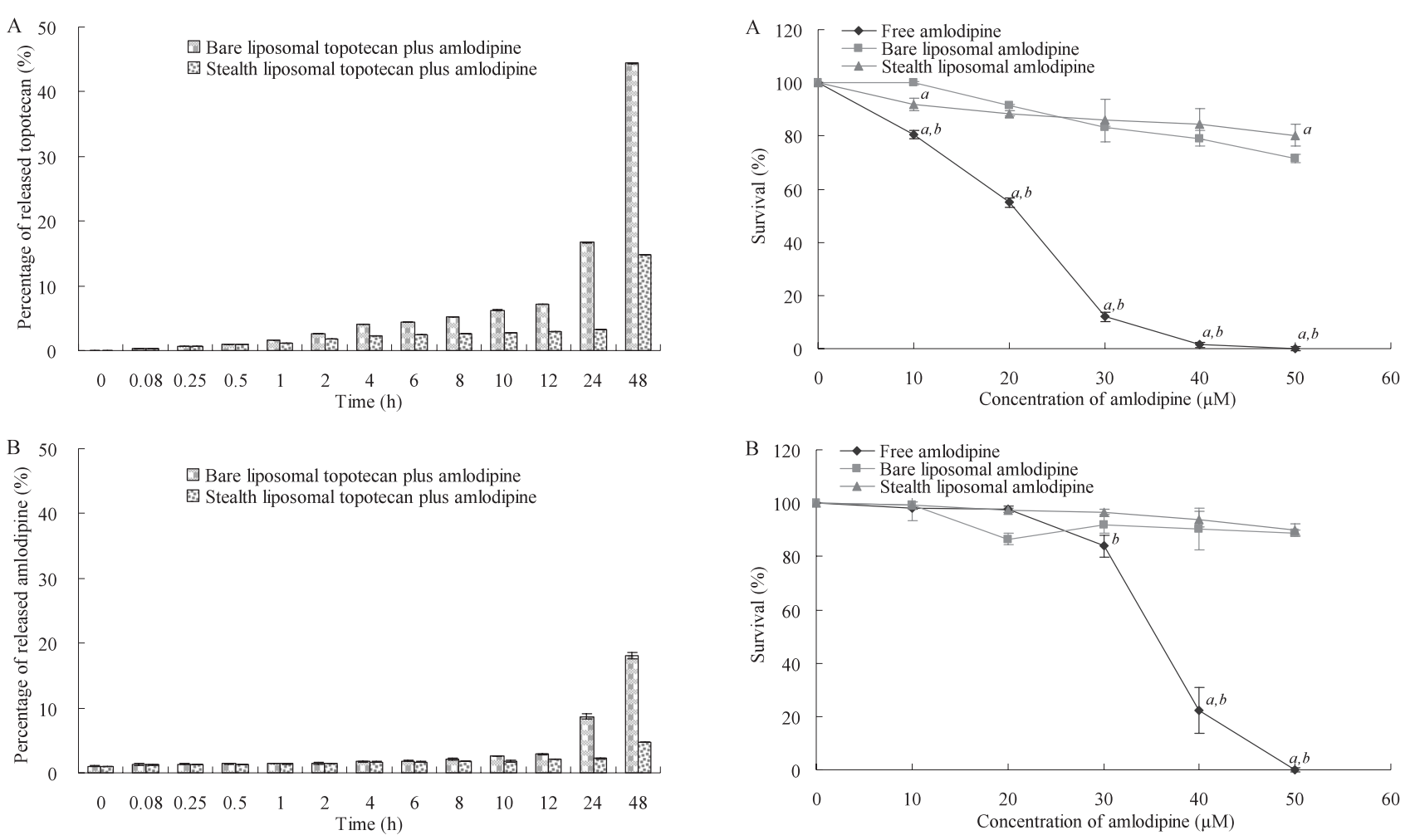

Fig. 1. In Vitro Release of Topotecan (A) and Amlodipine (B) from Bare Liposomal Topotecan $(0.5 \mathrm{mg} / \mathrm{ml})$ Plus Amlodipine $(0.5 \mathrm{mg} / \mathrm{ml})$ and Stealth Liposomal Topotecan $(0.5 \mathrm{mg} / \mathrm{ml})$ Plus Amlodipine $(0.5 \mathrm{mg} / \mathrm{ml})$ in Murine Plasma

Data are presented as mean \pm S.D. $(n=3)$.

ine in two kinds of liposomes demonstrated a retarded release profile compared with the encapsulated topotecan. At the $48 \mathrm{hr}$ time point, more than $80 \%$ and $95 \%$ amlodipine were still retained in bare liposomal topotecan plus amlodipine and stealth liposomal topotecan plus amlodipine, respectively. However, $44.38 \%$ and $14.79 \%$ topotecan released from bare liposomal toptecan plus amlodipine and stealth liposomal topotecan plus amlodipine, respectively (Fig. 1A and 1B).

\section{Antiproliferative Effects of Amlodipine Formu- lations}

The antiproliferative effects of various amlodipine formulations on S180 and MCF-7 cells are depicted in Fig. 2A and 2B, respectively. Free amlodipine alone exhibited a strong antiproliferative effect on S180 cells, showing a dose dependent manner (Fig. 2A). In particular, the inhibitory rate (as an indicator of the antiproliferative effect) to S180 cells of amlodipine was above $80 \%$ at higher concentrations $(\geq 30 \mu \mathrm{M})$. Free amlodipine

Fig. 2. Effects of Various Amlodipine Formulations on the Proliferation of S180 (A) and MCF-7 (B) Cells

Cells were incubated with the indicated concentrations of various amlodipine formulations for $48 \mathrm{hr}$ and the survival rates (\%) were measured using MTT assay. Each experiment was repeated in triplicate. Data are presented as mean \pm S.D. $(n=3) . a, p<0.05$, vs. bare liposomal amlodipine; $b, p<0.05$, vs. stealth liposomal amlodipine.

also showed an antiporliferative effect on MCF7 cells but was minimal (inhibitory rate $<5 \%$ ) at lower concentrations $(\leq 20 \mu \mathrm{M})$, while the inhibitory rate was gradually increased in the range of $30 \mu \mathrm{M}$ and $50 \mu \mathrm{M}$, exhibiting a dose dependent manner (Fig. 2B). However, the antiproliferative effects of liposomal amlodipine formulations were comparatively attenuated and did not show overt augmentations with their drug concentrations increasing.

\section{Additive Effects of Amlodipine Formulations}

The additive effects on the proliferation of S180 and MCF-7 cells are depicted in Fig. 3. Results showed that the antiproliferative effect of topotecan was added by co-treating amlodipine at different levels in both cell lines. In details, free topotecan demonstrated a strong antiproliferative effect on S180 cells and the inhibitory rates were in the range from $42.46-68.25 \%$ when the topotecan concentration treated was from $2.5-20 \mu \mathrm{M}$. After a concentration of topotecan $(2.5,5,10,15$ or $20 \mu \mathrm{M})$ was co- 

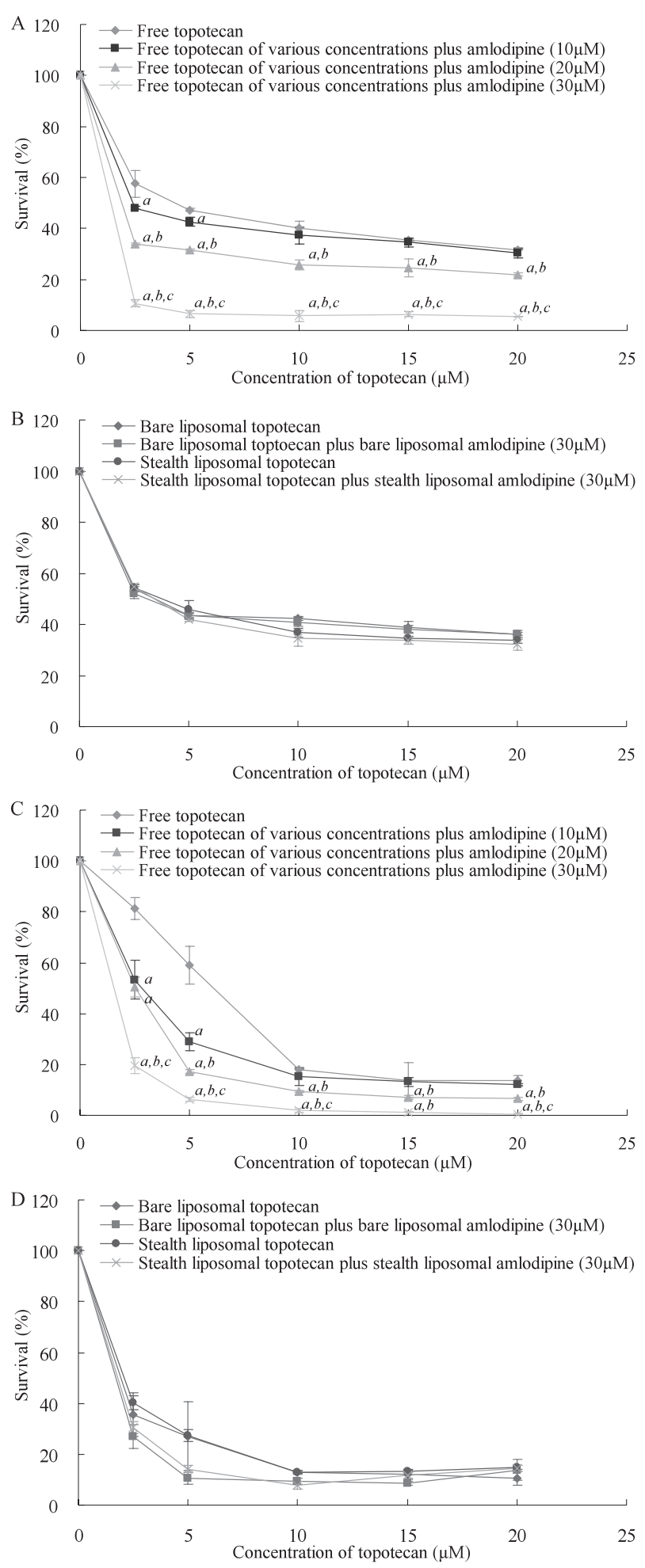

Fig. 3. Effects of Various Topotecan Formulations Co-treated with the Same Amlodipine Formulations on the Proliferation of S180 (A, B) and MCF-7 Cells (C, D)

Cells were incubated with the indicated concentrations of drugs for $48 \mathrm{hr}$ and the survival rates (\%) were measured using MTT assay. Data are presented as mean \pm S.D. $(n=3) . a, p<0.05$, vs. free topotecan; $b, p<0.05, v s$. free topotecan of various concentrations cotreated with free amlodipine $(10 \mu \mathrm{M}) ; c, p<0.05, v s$. free topotecan of various concentrations co-treated with free amlodipine $(20 \mu \mathrm{M})$. treated with 10,20 or $30 \mu \mathrm{M}$ of free amlodipine, respectively, the antiproliferative effect on S180 cells was gradually increased, exhibiting an amlodipine dose dependent manner (Fig. 3A). As a representative case, after a concentration of free topotecan $(10 \mu \mathrm{M})$ was co-treated with a fixed concentration of free amlodipine $(30 \mu \mathrm{M})$, the inhibitory rate to $\mathrm{S} 180$ cells was increased by $34.26 \%$, showing an obvious additive effect. However, the additive effect on the antiproliferative effect of bare or stealth liposomal topotecan on S180 cells seemed to be attenuated by liposomal encapsulation of amlodipine (Fig. 3B).

In addition, free topotecan was very effective in inhibiting the growth of MCF-7 cells, showing a dose dependent manner. When the topotecan concentration treated was from $2.5-20 \mu \mathrm{M}$, the inhibitory rates were in the range from $18.65-86.40 \%$. Moreover, when a concentration of topotecan (2.5, $5,10,15$ or $20 \mu \mathrm{M}$ ) was co-treated with 10,20 or $30 \mu \mathrm{M}$ of free amlodipine, respectively, the antiproliferative effect on MCF-7 cells was gradually increased, exhibiting an amlodipine dose dependent manner. As a typical value, after a concentration of free topotecan $(5 \mu \mathrm{M})$ was co-treated with a fixed concentration of amlodipine $(30 \mu \mathrm{M})$, the inhibitory rate to MCF-7 cells was increased by $52.67 \%$ (Fig. 3C). Nonetheless, the additive effect on the antiproliferative effect of bare or stealth liposomal topotecan on MCF-7 cells was also attenuated by liposomal encapsulation of amlodipine (Fig. 3D).

\section{Apoptosis Assessment}

The apoptotic percentages of S180 cells after treating free topotecan or free amlodipine are depicted in Fig. 4A. Results showed that the inducing apoptotic effect of free topotecan in S180 cells within $12 \mathrm{hr}$ incubation period was minimal compared with that of control blank medium. In contrast, the inducing apoptotic effect of free amlodipine was elevated gradually with the concentration increasing in the range of $30 \mu \mathrm{M}$ and $50 \mu \mathrm{M}$ but minimal below $30 \mu \mathrm{M}$. In details, when the concentration of free amlodipine was increased from $30 \mu \mathrm{M}$ to $50 \mu \mathrm{M}$, the apoptotic percentage was increased significantly from $16.91 \%$ to $40.71 \%$, exhibiting a strong inducing apoptotic effect on S180 cells.

The apoptotic percentages of S180 cells after treating various topotecan formulations in combination with the same amlodipine formulations are depicted in Fig. 4B. The rank order for the induc- 

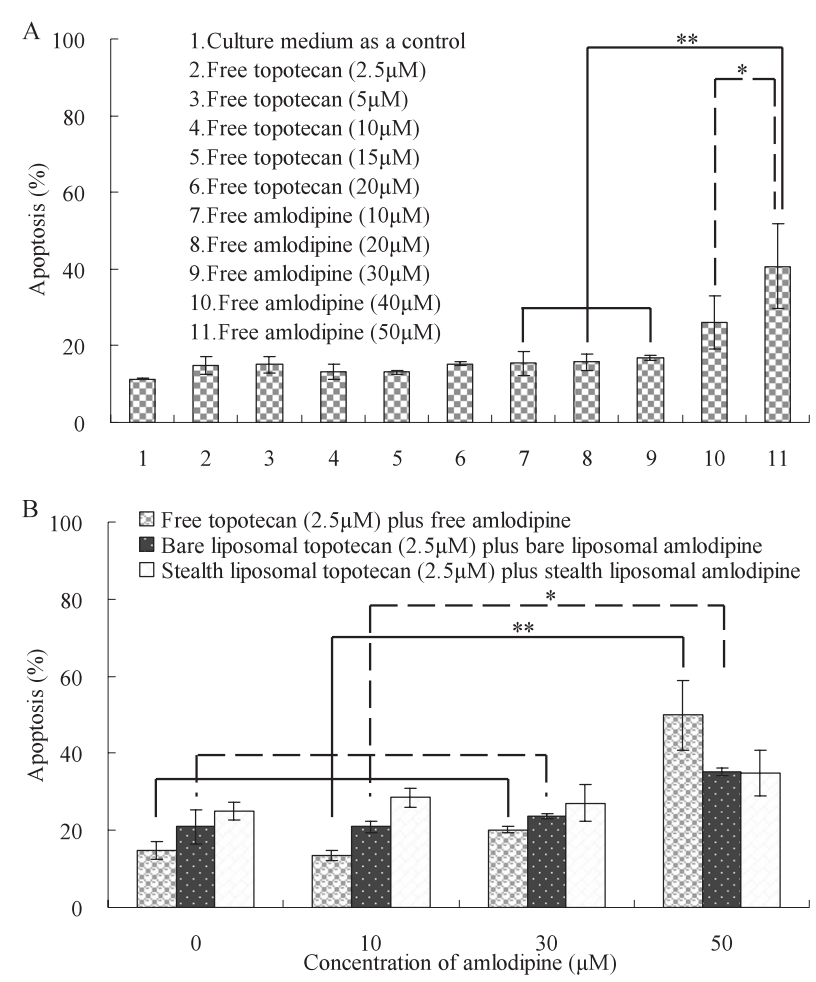

Fig. 4. Apoptotic Percentages (\%) of S180 Cells Induced by Free Topotecan and Free Amlodipine (A) as Well as Various Topotecan Formulations Co-treated with the Same Amlodipine Formulations (B)

Cells were incubated with the indicated concentrations of drugs for $12 \mathrm{hr}$ and the percentages of apoptotic cells were measured using flow cytometry assay with annexin V-FITC/propidium iodide staining. Data are presented as mean \pm S.D. $(n=3) .{ }^{*} p<0.05$; $^{* *} p<0.01$.

ing apoptotic effect of the three topotecan formulations was as follows: stealth liposomal topotecan $>$ bare liposomal topotecan $>$ free topotecan. All amlodipine formulations were able to increase the apoptotic percentages of S180 cells induced by the same topotecan formulations, respectively. In particular, free amlodipine showed a strong additive effect on the inducing apoptotic effect of free topotecan. The apoptotic percentage induced by free topotecan at $2.5 \mu \mathrm{M}$ was slight $(14.78 \%)$, but strengthened significantly by adding free amlodipine at $30 \mu \mathrm{M}(20.19 \%)$ or $50 \mu \mathrm{M}(49.93 \%)$. Bare liposomal amlodipine and stealth liposomal amlodipine at higher concentration $(50 \mu \mathrm{M})$ had the additive inducing apoptotic effects too, but were not significant compared with free amlodipine. For example, after co-treating a fixed concentration of bare liposomal topotecan $(2.5 \mu \mathrm{M})$ with $10 \mu \mathrm{M}, 30 \mu \mathrm{M}$ or $50 \mu \mathrm{M}$ bare liposomal amlodipine, the apoptotic percentages were $20.95 \%, 23.62 \%$ and $35.35 \%$, respectively.

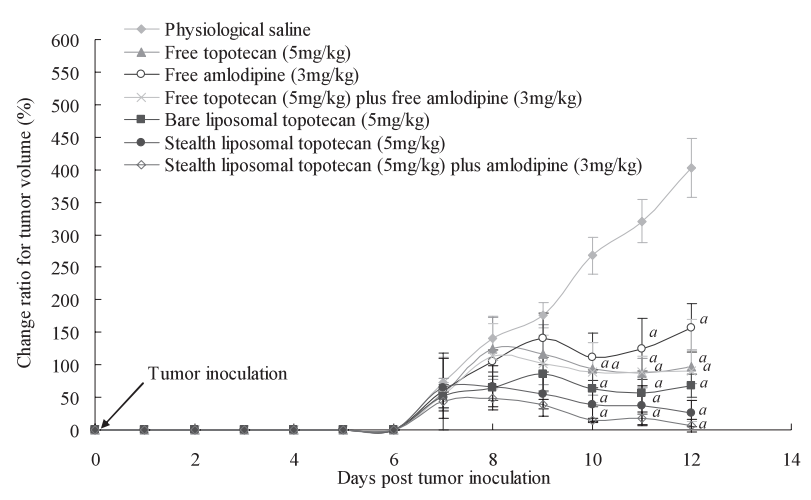

Fig. 5. Effects of Physiological Saline, Free Topotecan $(5 \mathrm{mg} / \mathrm{kg})$, Free Amlodipine $(3 \mathrm{mg} / \mathrm{kg})$, Free Topotecan $(5 \mathrm{mg} / \mathrm{kg})$ Plus Free Amlodipine $(3 \mathrm{mg} / \mathrm{kg})$, Bare Liposomal Topotecan $(5 \mathrm{mg} / \mathrm{kg})$, Stealth Liposomal Topotecan $(5 \mathrm{mg} / \mathrm{kg})$ and Stealth Liposomal Topotecan $(5 \mathrm{mg} / \mathrm{kg}$ ) Plus Amlodipine $(3 \mathrm{mg} / \mathrm{kg})$ on the $\mathrm{S} 180$ Xenografts in Male ICR Mice

Approximately $2 \times 10^{6} \mathrm{~S} 180$ cells derived from ascites fluid were subcutaneously injected into the right armpits of mice. On the 6th, 8th and 10th day post tumor inoculation, physiological saline (as a blank control) and indicated drug formulations were given to mice via tail vein, respectively. Data are presented as mean \pm S.E. $(n=5-6) . a, p<$ $0.05, v s$. physiological saline treated group.

\section{Tumor Growth Inhibition in Mice}

The change ratios for tumor volume (\%) are depicted in Fig. 5. After S180 cells were subcutaneously injected into the armpits of mice, the tumor masses appeared on the 4th day. Compared with the control group, the inhibitory activities on tumor growth were evidently observed in all groups treated with drug formulations but at different levels. Briefly, both free topotecan $(5 \mathrm{mg} / \mathrm{kg})$ and free amlodipine $(3 \mathrm{mg} / \mathrm{kg})$ showed inhibitive activities on S180 xenografts of male ICR mice, but none of them seemed to inhibit the continuing growth trend of tumors. In addition, the combination of free topotecan $(5 \mathrm{mg} / \mathrm{kg})$ plus free amlodipine $(3 \mathrm{mg} / \mathrm{kg})$ exerted a similar activity on the tumor growth compared with free topotecan alone. Bare liposomal topotecan $(5 \mathrm{mg} / \mathrm{kg})$ showed stronger inhibitive activity compared with free topotecan $(5 \mathrm{mg} / \mathrm{kg})$, but it did not retard the continuing tumor growth trend of S180 xenografts as well. However, mice treated with stealth liposomal topotecan $(5 \mathrm{mg} / \mathrm{kg})$ or stealth liposomal topotecan $(5 \mathrm{mg} / \mathrm{kg})$ plus amlodipine $(3 \mathrm{mg} / \mathrm{kg})$ exhibited a gradual shrinking trend on the tumor growth after the 7 th day.

From the 11th day post tumor inoculation, change ratios for tumor volume treated with various drug formulations were significantly lower compared with those treated with physiological saline $(p<0.05)$. In brief, the rank order for the in- 

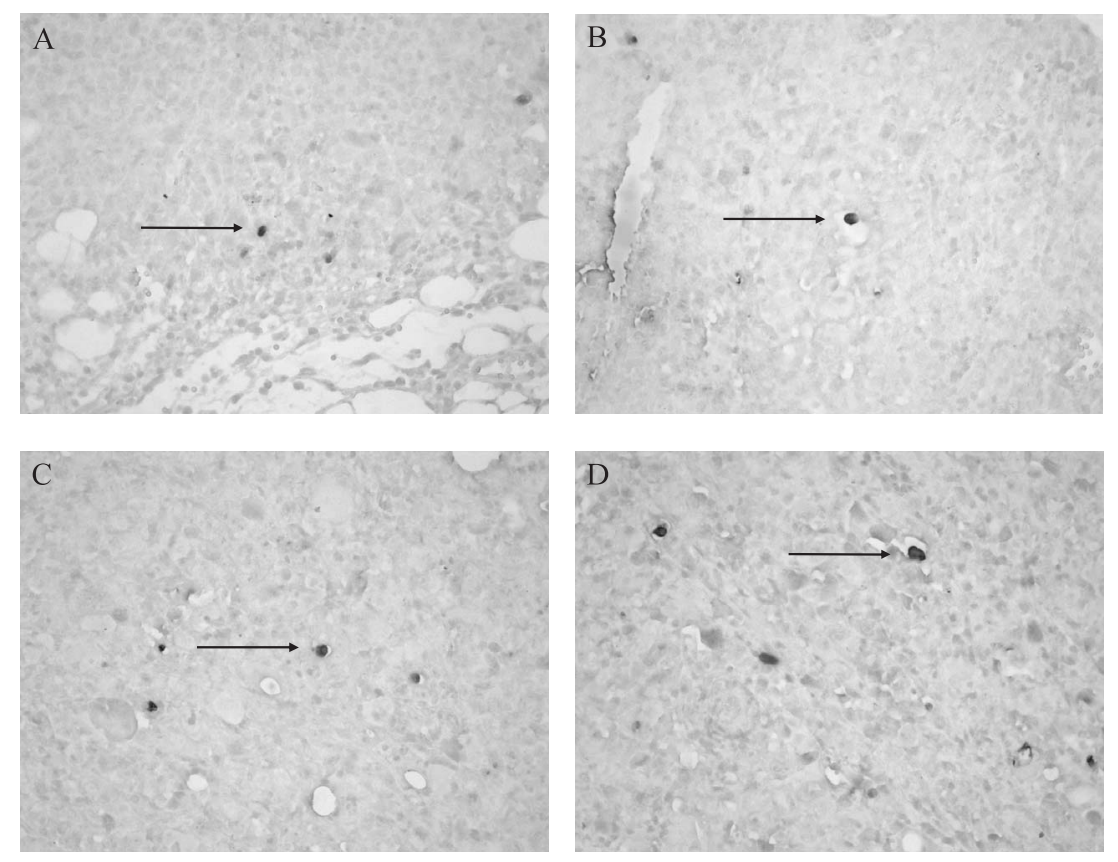

Fig. 6. Paraffin Sections Showing TUNEL-labeled Cells in the Tumor Tissues on the 13th Day after Inoculation of S180 Cells in the Male ICR Mice (Magnification, $\times 400$ )

Apoptotic cells (shown by arrowhead) are characterized by a dense staining of nuclei. The S180 xenografted mice were given intravenously with physiological saline as a blank control (A), free topotecan $(5 \mathrm{mg} / \mathrm{kg}$ ) (B), stealth liposomal topotecan $(5 \mathrm{mg} / \mathrm{kg})(\mathrm{C})$ and stealth liposomal topotecan $(5 \mathrm{mg} / \mathrm{kg})$ plus amlodipine $(3 \mathrm{mg} / \mathrm{kg})(\mathrm{D})$, respectively.

hibitive activities on the tumor growth was as follows: stealth liposomal topotecan $(5 \mathrm{mg} / \mathrm{kg})$ plus amlodipine $(3 \mathrm{mg} / \mathrm{kg})>$ stealth liposomal topotecan $(5 \mathrm{mg} / \mathrm{kg})>$ bare liposomal topotecan $(5 \mathrm{mg} / \mathrm{kg})$ $>$ free topotecan $(5 \mathrm{mg} / \mathrm{kg})$ plus free amlodipine $(5 \mathrm{mg} / \mathrm{kg})>$ free topotecan $(5 \mathrm{mg} / \mathrm{kg})>$ free amlodpine $(3 \mathrm{mg} / \mathrm{kg})>$ physiological saline (the control group).

\section{TUNEL Analysis}

The TUNEL assay showed that the apoptotic percentages were $2.0 \pm 1.4 \%$ for the group treated with physiological saline (Fig. 6A), $2.7 \pm 3.6 \%$ for the group treated with free topotecan $(5 \mathrm{mg} / \mathrm{kg}$ ) (Fig. 6B), $5.3 \pm 2.5 \%$ for the group treated with stealth liposomal topotecan $(5 \mathrm{mg} / \mathrm{kg}$ ) (Fig. 6C) and $6.7 \pm 1.5 \%$ for the group treated with stealth liposomal topotecan $(5 \mathrm{mg} / \mathrm{kg})$ plus amlodipine $(3 \mathrm{mg} / \mathrm{kg})$ (Fig. 6D).

\section{DISCUSSION}

We have previously demonstrated that stealth liposomal topotecan plus amlodipine displayed an optimal anti-tumor activity in the MDR HL-60 xenografts in nude mice, showing a potential value for clinical evaluations. The optimal anti-tumor activity was associated with the reversing MDR and additive inducing apoptotic effects of amlodipine together with multiple beneficial biological properties of stealth liposomal encapsulation. ${ }^{1)}$ Besides leukemia cells, we postulated that amlodipine might be effective in a more diversified pool of tumor cells as mentioned earlier. Therefore, we further studied the suitability of the stealth liposomal topotecan plus amlodipine against non-resistant murine sarcoma cell line S180 and human breast cancer cell line MCF-7.

To obtain a repeatable result for the construction of stealth liposomal topotecan plus amlodipine, the liposomes were re-prepared and characterized in the present study. Compared with passive liposome-loading methods, the ammonium sulfate gradient method is a superior encapsulation procedure, which results in high drug encapsulation efficiency. When ammonium sulfate is encapsulated into liposomes followed by removing the external ammonium sulfate of liposomes using the dialysis method, a transmembrane $\mathrm{pH}$ gradient is thus established which actively drive drugs as weak bases into the inner acidic aqueous core of liposomes, as re- 
ported previously. ${ }^{34)}$ Similar to a former study using the ionophore-mediated proton gradient loading procedure ${ }^{12,16)}$ which reached $\geq 90 \%$ encapsulation efficiency for topotecan, we also obtained stable topotecan-loaded liposomes with a higher encapsulation efficiency ( $\geq 95 \%)$. In addition, a previous study showed that amlodipine could be incorporated into liposomes under a stream of nitrogen by sonication, but the encapsulation efficiency was too low $(41.6 \%){ }^{35)}$ In the present study, we successfully incorporated amlodipine together with topotecan into liposomes using the ammonium sulfate gradient method and reached $\geq 90 \%$ encapsulation efficiency for both drugs. Therefore, the repeated results indicate that the developed method for preparation of the stealth liposomal topotecan plus amlodipine is coincident with our previous report ${ }^{1)}$ and might be suitable for the future scale-up production.

The particle size of liposomes significantly affects their pharmacokinetics properties, toxicities and anti-tumor activities of the encapsulated drugs in vivo. It was reported that the half lives of liposomes were extended in blood circulation at a mean diameter of $100 \mathrm{~nm}$. On the one hand, liposomes with larger particle size are more likely to be captured by the cells of the RES in liver and spleen. On the other hand, those with particle size below $100 \mathrm{~nm}$ are easily taken up by the hepatic parenchymal cells because these liposomes can pass through the liver sinusoidal capillaries which contain "pores" smaller than $100 \mathrm{~nm} .{ }^{36)}$ In the present study, stealth liposomal topotecan plus amlodipine showed a suitable mean particle size $(\sim 118 \mathrm{~nm})$ and homogeneous distribution (PDI $=0.173$ ), indicating that it may have a superior efficiency of extravasation from the "pores" in the capillary endothelium of tumor vasculature leading to an increased accumulation within the interstitial spaces of tumor tissues. $^{12)}$

Zeta potential value is another indicator for characterizing liposomes or nanoparticles albeit its exact role remains unclear. It is deemed as a factor for assessing the physical stability of liposomes. As the absolute value of zeta potential increases, the liposomes might be dispersed more stably due to the increased electric repulsive force between liposomal surfaces. ${ }^{30)}$ In the present study, the absolute zeta poteintal value of stealth liposomal topotecan plus amlodipine was significantly higher than that of bare liposomal topotecan plus amlodipine, indicating that stealth liposomal topotecan plus amlodipine might be more stable for storage. These results are consistent with what we observed that the stealth liposomal topotecan plus amlodipine was less likely to coagulate during the $4^{\circ} \mathrm{C}$ storage in refrigerator within 6 month (data not shown).

The release of drugs from liposomes may respond to the leaky status during storage or after in vivo administration. For comparison, the release profiles of bare liposomal topotecan plus amlodipine and stealth liposomal topotecan plus amlodipine in murine plasma were all evaluated using the dialysis method. In both cases, the release process for the two types of liposomes during the observation period was composed of a retarded release phase from $0 \mathrm{hr}$ to $12 \mathrm{hr}$ and a sharp increased release phase from $12 \mathrm{hr}$ to $48 \mathrm{hr}$. Comparatively, evident decreases in release rates were observed for both topotecan and amlodipine from stealth liposomes, indicating that stealth liposomal topotecan plus amlodipine would be more stable in the blood circulation until they reach the tumor vasculature and are internalized by the tumor tissues. This phenomenon could be partly attributed to the increased bilayer rigidity of PEGylated stealth liposomes compared with bare ones. ${ }^{13)}$ In addition, amlodipine was released in a significantly reduced rate compared with topotecan. It has been reported previously that liposomal topotecan exhibited a polymorphic precipitated structure within the inner aqueous core and topotecan was released in a faster rate than those of drugs from liposomal doxorubicin or liposomal mitoxantrone. ${ }^{16)}$ However, little was known about the structure of amlodipine-loaded liposomes and the interaction between topotecan and amlodipine in the liposomes containing two drugs. Most likely, a more stabilized structure of amlodipine is formed in amlodipine-loaded liposomes and the topotecan precipitates retard the release rate of amlodipine from bare liposomal topotecan plus amlodipine and stealth liposomal topotecan plus amlodipine.

MTT assays demonstrate that free amlodipine is potent against non-resistant solid tumor S180 and MCF-7 cells. As the concentration of free amlodipine increased, the antiproliferative effect was increased markedly, showing a dose dependent manner. However, the antiproliferative effects of bare liposomal amlodipine and stealth liposomal amlodipine were attenuated significantly compared with free amlodipine. This phenomenon might be associated with the decreased intracellular uptake of amlodipine due to liposomal encapsulation in vitro. The drugs encapsulated in liposomes enter tumor cells mainly by three approaches: passive diffusion, 
membrane fusion and endocytosis. Besides passive diffusion, membrane fusion and endocytosis may also play important roles in which topotecan or amlodipine accumulates into tumor cells. Therefore, in addition to the release rates of drugs encapsulated in liposomes, the efficiencies of membrane fusion and endocytosis could influence the antiproliferative effects of drug-loaded liposomes as well. However, the retarded release rate of encapsulated amlodipine from liposomes might be an important factor that contributes to the decreased intracellular uptake of the agent in vitro. Drug-loaded liposomes may display some leakage as the liposome bilayer interacted with cell surface proteins during the incubation period, which provides the source of free drug for intracellular-directed diffusion. ${ }^{11)}$ Due to the retarded release rate of encapsulated amlodipine, it is possible that only a small proporation of encapsulated amlodipine was released during the incubation period so that the amount of amlodipine that could be passively diffused to tumor cells was not sufficient to exert strong antiproliferative effect.

In addition, free topotecan is effective in inhibiting the growth of S180 and MCF-7 cells and cotreating with free amlodipine additively improves the antiproliferative effect of free topotecan. We have previously shown that amlodipine enhanced the antiproliferative effect of topotecan in resistant and non-resistant leukemia cell line MDR HL-60 and HL-60, showing an additive effect. ${ }^{1)}$ In the present study, we found that the additive antiproliferative effect of amlodipine seemed to be stronger in the two non-resistant S180 and MCF-7 cell lines. In particular, when the concentration of free amlodipine reaches to $40 \mu \mathrm{M}$ or above, no viable cells could be detected using MTT assay, indicating that free amlodipine might be more toxic to solid tumor cells. However, no obvious increase in the antiproliferative effect of bare or stealth liposomal topotecan was observed after co-treating bare or stealth liposomal amlodipine at the indicated concentration $(30 \mu \mathrm{M})$, respectively. This phenomenon might be attributed to the retarded release rate of amlodipine from liposomes, which leads to a decreased amount of amlodipine that could be passively diffused into tumor cells together with topotecan, as discussed above.

In our preliminary study, the flow cytometry assay was performed under a $36 \mathrm{hr}$ incubation period. Both topotecan and amlodipine exerted stronger inducing apoptotic effects on S180 cells, but the apoptotic percentage of blank control was also increased due to the exhaustion of medium nutrients. How- ever, when the incubation period was reduced to $12 \mathrm{hr}$, free topotecan at all concentrations displayed very little effect in triggering apoptosis of S180 cells. Therefore, the $12 \mathrm{hr}$ incubation period might not be sufficient for topotecan to induce apoptosis of $\mathrm{S} 180$ cells since topotecan is a cell cycle specific anti-tumor agent and the prolonged exposure period of topotecan to tumor cells is beneficial for the agent to induce apoptosis. We also found that the rank order for the inducing apoptotic effects of various topotecan formulations was stealth liposomal topotecan $>$ bare liposomal topotecan $>$ free topotecan. This phenomenon could be explained by the fact that the encapsulation of topotecan into the acidic medium of the inner core of liposomes is favorable for protection of the active lactone species, as mentioned previously. Our findings are also consistent with a previous study comprising a topotecan hydrolysis test in which the authors found that free topotecan underwent a rapid hydrolysis with a short half life of approximately 21 min at physiological $\mathrm{pH}$ condition in plasma. In contrast, the half life for converting topotecan from the active lactone species to the inactive carboxylate species of stealth liposomal topotecan or bare liposomal topotecan was $5.58 \mathrm{hr}$ or $4.31 \mathrm{hr}$, respectively. Even after $10 \mathrm{hr}$ incubation of stealth liposomal topotecan or bare liposomal topotecan in the same condition, approximately $29 \%$ or $20 \%$ of the encapsulated topotecan remained as the lactone species, respectively. ${ }^{13)}$ Therefore, we concluded that stealth liposomal topotecan was more favorable for the protection of lactone species, which thereby leads to the optimal inducing apoptotic effect among the three topotecan formulations.

In addition, it was noted that no significant differences were observed in the inhibitory rates to S180 cells between free topotecan (Fig. 3A) and liposomal topotecan (Fig. 3B) in the full concentration range. However, evident differences could be found in the induced apoptotic percentages between free topotecan and liposomal topotecan (Fig. 4B). This discrepancy might be associated with two aspects. Firstly, the inhibition to S180 cells could be caused by the effects either from the direct exposure killing by topotecan or the inducing apoptotic effect of this agent leading to the suicide of the cells, or from both together. ${ }^{1)}$ Accordingly, the inhibitory rates may not be necessarily coincident with the induced apoptotic percentages. In addition, the discrepancy may also be caused by the formulation factors which resulted in different interaction periods 
between drugs and tumor cells. The mechanisms deserve further exploration in the future research.

Compared with free topotecan, a relatively stronger inducing apoptotic effect on S180 cells was obtained by free amlodipine, in particular, at higher concentrations (above $40 \mu \mathrm{M}$ ). These results further substantiate that amlodipine is a potential anti-tumor agent capable of inducing apoptosis of tumor cells after a short incubation period. $1,20,21$ ) Also, different levels of additive inducing apoptotic effects of various amlodipine formulations were observed in flow cytometry assay. The rank order for the additive inducing apoptotic effects of various amlodipine formulations was free amlodipine $>$ bare liposomal amlodipine $>$ stealth liposomal amlodipine. The results were consistent with our previous study about the intracellular uptake of various amlodipine formulations in S180 cells evaluated by confocal microscopy (data not shown). After S180 cells were incubated with various amlodipine formulations at a fixed concentration $(30 \mu \mathrm{M})$ for $1 \mathrm{hr}$, the rank order for the intracellular fluorescent intensities (as an indicator of the intracellular amlodipine concentrations) was free amlodipine $>$ bare liposomal amlodipine $>$ stealth liposomal amlodipine, indicating that free amlodipine has the optimal intracellular accumulation leading to its best additive inducing apoptotic effect. As mentioned above, the retarded release profile of amlodipine from bare liposomal amlodipine and stealth liposomal amlodipine might be responsible for their attenuated additive inducing apoptotic effect observed in the flow cytometry assays.

The in vivo inhibitive activities of various treatments indicate that stealth liposomal topotecan plus amlodipine has the optimal anti-tumor activity in the ICR mice bearing S180 xenografts. Multiple factors would be associated with the optimal antitumor activity of stealth liposomal toptoecan plus amlodipine. Firstly, stealth liposomes with smaller particle size around $100 \mathrm{~nm}$ are able to extravasate through the "pores" of the capillary endothelium of tumor vasculature in a more efficient manner, resulting in an increased accumulation of those liposomes in the interstitial spaces of tumor tissues. Secondly, since topotecan is a cell cycle specific anti-tumor agent, increased exposure period of topotecan to tumor cells is favorable for its anti-tumor activity. Therefore, the improved anti-tumor activity could be attained using stealth liposomes because they exhibit prolonged half lives and sustained drug release profiles in vivo. Thirdly, by encapsulating topote- can into the inner acidic core of stealth liposomes, the active lactone species could be further protected from hydrolysis and an improved anti-tumor activity is thus obtained. Finally, the co-treatment of amlodipine, as a potential anti-tumor agent displaying evident additive antiproliferative and inducing apoptotic effects on S180 cells, is also associated with the optimal anti-tumor activity of stealth liposomal topotecan plus amlodipine. By incorporating topotecan with amlodipine together into the stealth liposomes, the cytotoxic agent and additive agent can be simultaneously delivered to the tumor tissues, leading to an enhanced anti-tumor activity in the S180 xenografted mice. The results from TUNEL analysis also reflected that stealth liposomal topotecan plus amlodipine exerted the best inducing apoptotic effect in the S180 xenografts of tumor-bearing ICR mice, which contributed to its overall optimal anti-tumor activity in vivo.

In conclusion, the construction of stealth liposomal topotecan plus amlodipine is repeatable with stable high encapsulation efficiencies for both agents. Amlodipine demonstrated strong antiproliferative and inducing apoptotic effects, which markedly potentiated the anti-tumor activity of topotecan on the non-resistant solid tumor S180 and MCF-7 cell lines in vitro. Stealth liposomal topotecan plus amlodipine achieved the optimal inhibitive activity on the growth of S180 xenografts in tumorbearing ICR mice due to their suitable particle size distribution, prolonged drugs exposure, increased proportion of active lactone species as well as additive antiproliferative and inducing apoptotic effects of amlodipine. As a continued study, it is found that the stealth liposomal topotecan plus amlodipine showed a satisfactory anti-tumor activity in nonresistant solid tumor cell lines, suggesting that it deserves further clinical evaluations.

Acknowledgements This paper was supported by Grant of National Science Foundation of China (No. 30430760).

\section{REFERENCES}

1) Li, X., Ruan, G. R., Lu, W. L., Hong, H. Y., Liang, G. W., Zhang, Y. T., Liu, Y., Long, C., Ma, X., Yuan, L., Wang, J. C., Zhang, X. and Zhang, Q. (2006) A novel stealth liposomal topotecan with amlodipine: apoptotic effect is associated with deletion of intracellular $\mathrm{Ca}^{2+}$ by amlodipine thus leading to an en- 
hanced anti-tumor activity in leukemia. J. Control. Release, 112, 186-198.

2) Ozben, T. (2006) Mechanisms and strategies to overcome multiple drug resistance in cancer. FEBS Lett., 580, 2903-2909.

3) Wong, H. L., Bendayan, R., Rauth, A. M., Li, Y. and Wu, X. Y. (2007) Chemotherapy with anticancer drugs encapsulated in solid lipid nanoparticles. $A d v$. Drug Deliv. Rev., 59, 491-504.

4) Limtrakul, P., Siwanon, S., Yodkeeree, S. and Duangrat, C. (2007) Effect of Stemona curtisii root extract on P-glycoprotein and MRP-1 function in multidrug-resistant cancer cells. Phytomedicine, 14, 381-389.

5) Wang, Y., Yu, L., Han, L., Sha, X. and Fang, X. (2007) Difunctional Pluronic copolymer micelles for paclitaxel delivery: synergistic effect of folatemediated targeting and Pluronic-mediated overcoming multidrug resistance in tumor cell lines. Int. J. Pharm., 337, 63-73.

6) Simoni, D., Rizzi, M., Rondanin, R., Baruchello, R., Marchetti, P., Invidiata, F. P., Labbozzetta, M., Poma, P., Carina, V., Notarbartolo, M., Alaimo, A. and D'Alessandro, N. (2008) Anti-tumor effects of curcumin and structurally beta-diketone modified analogs on multidrug resistant cancer cells. Bioorg. Med. Chem. Lett., 18, 845-849.

7) Andresen, T. L., Jensen, S. S. and Jorgensen, K. (2005) Advanced strategies in liposomal cancer therapy: problems and prospects of active and tumor specific drug release. Prog. Lipid Res., 44, 68-97.

8) Gabizon, A., Goren, D., Horowitz, A. T., Tzemach, D., Lossos, A. and Siegal, T. (1997) Longcirculating liposomes for drug delivery in cancer therapy: a review of biodistribution studies in tumor-bearing animals. Adv. Drug Deliv. Rev., 24, 337-344.

9) Lukyanov, A. N., Elbayoumi, T. A., Chakilam, A. R. and Torchilin, V. P. (2004) Tumor-targeted liposomes: doxorubicin-loaded long-circulating liposomes modified with anti-cancer antibody. J. Control. Release, 100, 135-144.

10) Plassat, V., Martina, M. S., Barratt, G., Ménager, C. and Lesieur, S. (2007) Sterically stabilized superparamagnetic liposomes for MR imaging and cancer therapy: Pharmacokinetics and biodistribution. Int. J. Pharm., 344, 118-127.

11) Xiong, X. B., Huang, Y., Lu, W. L., Zhang, X., Zhang, H., Nagai, T. and Zhang, Q. (2005) Enhanced intracellular delivery and improved antitumor efficacy of doxorubicin by sterically stabilized liposomes modified with a synthetic RGD mimetic. J. Control. Release, 107, 262-275.
12) Tardi, P., Choice, E., Masin, D., Redelmeier, T., Bally, M. and Madden, T. D. (2000) Liposomal encapsulation of topotecan enhances anticancer efficacy in murine and human xenograft models. Cancer Res., 60, 3389-3393.

13) Dadashzadeh, S., Vali, A. M. and Rezaie, M. (2008) The effect of PEG coating on in-vitro cytotoxicity and in-vivo disposition of topotecan loaded liposomes in rats. Int. J. Pharm., 353, 251-259.

14) Akbas, S. H., Timur, M. and Ozben, T. (2005) The effect of quercetin on topotecan cytotoxicity in MCF-7 and MDA-MB 231 human breast cancer cells. J. Surg. Res., 125, 49-55.

15) Emerson, D. L. (2000) Liposomal delivery of camptothecins. Pharm. Sci. Technol. Today, 3, 205-209.

16) Abraham, S. A., Edwards, K., Karlsson, G., Hudon, N., Mayer, L. D. and Bally, M. B. (2004) An evaluation of transmembrane ion gradient-mediated encapsulation of topotecan within liposomes. J. Control. Release, 96, 449-461.

17) Wong, H. L., Bendayan, R., Rauth, A. M. and Wu, X. Y. (2006) Simultaneous delivery of doxorubicin and GG918 (Elacridar) by new polymer-lipid hybrid nanoparticles (PLN) for enhanced treatment of multidrug-resistant breast cancer. J. Control. Release, 116, 275-284.

18) Leitner, H. M., Kachadourian, R. and Day, B. J. (2007) Harnessing drug resistance: using $A B C$ transporter proteins to target cancer cells. Biochem. Pharmacol., 74, 1677-1685.

19) Kim, H. S., Min, Y. D. and Choi, C. H. (2001) Double-edged sword of chemosensitizer: increase of multidrug resistance protein (MRP) in leukemic cells by an MRP inhibitor probenecid. Biochem. Biophys. Res. Commun., 283, 64-71.

20) Yoshida, J., Ishibashi, T. and Nishio, M. (2007) G1 cell cycle arrest by amlodipine, a dihydropyridine $\mathrm{Ca}^{2+}$ channel blocker, in human epidermoid carcinoma A431 cells. Biochem. Pharmacol., 73, 943953.

21) Yoshida, J., Ishibashi, T. and Nishio, M. (2004) Anti-tumor effects of amlodipine, a $\mathrm{Ca} 2+$ channel blocker, on human epidermoid carcinoma A431 cells in vitro and in vivo. Eur. J. Pharmacol., 492, 103-112.

22) Li, X., Lu, W. L., Liang, G. W., Ruan, G. R., Hong, H. Y., Long, C., Zhang, Y. T., Liu, Y., Wang, J. C., Zhang, X. and Zhang, Q. (2006) Effect of stealthy liposomal topotecan plus amlodipine on the multidrug-resistant leukaemia cells in vitro and xenograft in mice. Eur. J. Clin. Invest., 36, 409-418.

23) Yu, F., Yu, F., McGuire, P. M., Li, R. and Wang, R. (2007) Effects of Hydrocotyle sibthorpioides ex- 
tract on transplanted tumors and immune function in mice. Phytomedicine, 14, 166-171.

24) Qi, X. R., Maitani, Y., Nagai, T. and Wei, S. L. (1997) Comparative pharmacokinetics and anti-tumor efficacy of doxorubicin encapsulated in soybean-derived sterols and poly(ethylene glycol) liposomes in mice. Int. J. Pharm., 146, 31-39.

25) Hu, Y., Yang, Y., You, Q. D., Liu, W., Gu, H. Y., Zhao, L., Zhang, K., Wang, W., Wang, X. T. and Guo, Q. L. (2006) Oroxylin A induced apoptosis of human hepatocellular carcinoma cell line HepG2 was involved in its anti-tumor activity. Biochem. Biophys. Res. Commun., 351, 521-527.

26) Djuric, Z., Heilbrun, L. K., Lababidi, S., EverettBauer, C. K. and Fariss, M. W. (1997) Growth inhibition of MCF-7 and MCF-10A human breast cells by alpha-tocopheryl hemisuccinate, cholesteryl hemisuccinate and their ether analogs. Cancer Lett., 111, 133-139.

27) Chhipa, R. R., Singh, S., Surve, S. V., Vijayakumar, M. V. and Bhat, M. K. (2005) Doxycycline potentiates anti-tumor effect of cyclophosphamide in mice. Toxicol. Appl. Pharmacol., 202, 268-277.

28) Pedro, M., Ferreira, M. M., Cidade, H., Kijjoa, A., Bronze-da-Rocha, E. and Nascimento, M. S. (2005) Artelastin is a cytotoxic prenylated flavone that disturbs microtubules and interferes with DNA replication in MCF-7 human breast cancer cells. Life Sci., 77, 293-311.

29) Liu, J., Guo, L., Yin, F., Zheng, X., Chen, G. and Wang, Y. (2007) Characterization and anti-tumor activity of triethylene tetramine, a novel telomerase inhibitor. Biomed. Pharmacother., In Press.

30) Liu, J., Gong, T., Wang, C., Zhong, Z. and Zhang,
Z. (2007) Solid lipid nanoparticles loaded with insulin by sodium cholate-phosphatidylcholine-based mixed micelles: preparation and characterization. Int. J. Pharm., 340, 153-162.

31) Cui, F., Shi, K., Zhang, L., Tao, A. and Kawashima, Y. (2006) Biodegradable nanoparticles loaded with insulin-phospholipid complex for oral delivery: preparation, in vitro characterization and in vivo evaluation. J. Control. Release, 114, 242-250.

32) Mosmann, T. (1983) Rapid colorimetric assay for cellular growth and survival: application to proliferation and cytotoxicity assays. J. Immunol. Methods, 65, 55-63.

33) Soto-Cerrato, V., Llagostera, E., Montaner, B., Scheffer, G. L. and Perez-Tomas, R. (2004) Mitochondria-mediated apoptosis operating irrespective of multidrug resistance in breast cancer cells by the anticancer agent prodigiosin. Biochem. Pharmacol., 68, 1345-1352.

34) Haran, G., Cohen, R., Bar, L. K. and Barenholz, Y. (1993) Transmembrane ammonium sulfate gradients in liposomes produce efficient and stable entrapment of amphipathic weak bases. Biochim. Biophys. Acta, 1151, 201-215.

35) Ragno, G., Cione, E., Garofalo, A., Genchi, G., Ioele, G., Risoli, A. and Spagnoletta, A. (2003) Design and monitoring of photostability systems for amlodipine dosage forms. Int. J. Pharm., 265, 125132.

36) Nagayasu, A., Uchiyama, K. and Kiwada, H. (1999) The size of liposomes: a factor which affects their targeting efficiency to tumors and therapeutic activity of liposomal anti-tumor drugs. Adv. Drug Deliv. Rev., 40, 75-87. 